\title{
Critérios de avaliação de recurso digital e princípios de aprendizagem: o jogo Mission US no ensino de Língua Inglesa ${ }^{1}$
}

\author{
Franciele Knebel Centenaro Rocha - UFSM - fkcentenaro@ gmail.com
}

Resumo: Promover o ensino de Língua Inglesa na atualidade é ter diferentes recursos tecnológicos a favor do professor. Um destes recursos é o jogo digital, por ser uma ferramenta atrativa que fornece sensações de prazer além de, muitas vezes, ser desenvolvida em língua estrangeira. No entanto, nem todos os jogos são capazes de fomentar o ensino, fazendo-se necessário, o professor, analisar o recurso anterior a sua aplicação em sala de aula, a fim de identificar o seu potencial. Desta forma, a presente investigação aborda os critérios utilizados pela professora-pesquisadora em pesquisa de mestrado que foi realizada na Universidade Federal de Santa Maria no segundo semestre de 2015. O jogo analisado foi o Mission US e os critérios utilizados tem base na avaliação de recursos digitais e nos princípios de aprendizagem. Os resultados apontam para o potencial do jogo no ensino de Língua Inglesa.

Palavras-chave: ensino de Língua Inglesa; jogos digitais; critérios de avaliação e análise

\section{Digital resources evaluation criteria and learning principles: the game Mission US in the English language teaching}

Abstract: Promoting the English language teaching, today, it means having different technological resources in favor of the teacher. One of these resources is the digital game, which is an attractive tool that provides sensations of pleasure to its user, besides most of these technologies are developed in a foreign language. However, it is not all the games that are able to improve the education, it is necessary, the teacher, analyze the tool before applying it in the classroom, in a way to identify its potential. Therefore, this investigation discusses the criteria used by a researcher-teacher in a developed master study at Federal University of Santa Maria in the second semester of 2015. The analyzed game was Mission US and the criteria used was based on the digital resources evaluation and the learning principles. The results show that the analyzed game is a potential technology to be inserted in the English language teaching.

Key-words: English language teaching; digital games; evaluation and analysis criteria

\section{Introdução}

De acordo com Kenski (2005), as escolas deveriam provocar no educador uma profunda transformação de pensamentos, levando-o a refletir a respeito de como aliar o ensino em sala de aula com o uso das tecnologias emergentes, principalmente, ao buscar por alternativas pedagógicas que não sejam apenas aquelas voltadas para a digitalização ${ }^{2}$ do ensino já existente (Marinho, 2006; Marco, 2009; Sanches et al.,

\footnotetext{
${ }^{1}$ Este estudo faz parte da investigação de mestrado de Franciele Knebel Centenaro (2016), a qual foi apresentada e defendida no Programa de Mestrado Profissional de Tecnologias Educacionais em Rede, na Universidade Federal de Santa Maria, em 26/09/2016.

${ }^{2}$ Os autores abordam digitalização como sendo apenas a cópia virtual de material pedagógico sem alterar o modelo de aula tradicional, que não se baseia na autonomia e na interação do aluno com os recursos.
} 
2014). Nessa mesma direção, Moran (2013) destaca que o uso de tecnologias na educação traz expressivas transformações que corroboram com o seu uso em sala de aula, pois

com as tecnologias atuais a escola pode transformar-se em um conjunto de espaços ricos de aprendizagens significativas, presenciais e digitais, que motivam os alunos a aprender ativamente, a pesquisar o tempo todo, a serem pró-ativos, a saberem tomar iniciativas, a saber inter-agir (Moran, 2013, p. 30)

Tendo em vista que jogos digitais são ferramentas tecnológicas emergentes da atualidade e que podem auxiliar no desenvolvimento cognitivo do aluno e corroborar com o ensino de línguas (Centenaro, 2016; Peterson, 2012), faz-se necessário compreender de que maneira o professor pode avaliar este recurso antes de inseri-lo em contexto educacional. Assim, alguns estudos realizados com jogos (Centenaro; Reis, 2017; Reis; Gomes, 2014; Gee, 2005) verificaram a importância de analisar o recurso digital, e estabeleceram alguns critérios e elementos específicos de bons jogos, o que garante que os processos de ensino e aprendizagem sejam trabalhados e desenvolvidos de forma agregadora para o conhecimento do aluno.

Desta forma, compreendendo a importância dos jogos digitais para o ensino de línguas e a sua análise para verificar o seu potencial, este trabalho tem como foco: a) explanar sobre os dois critérios possíveis de serem utilizados para a análise desses tipos de jogos, os quais são a avaliação de recurso digital e os princípios de aprendizagem; b) apresentar a metodologia da pesquisa; c) detalhar a analise do jogo Mission US, bem como discutir os resultados coletados; d) e por fim, realizar as considerações finais.

Para tal, na primeira seção é discutido sobre a estrutura e características dos elementos que compõe a avaliação de recursos digitais elaborado por Reis e Gomes (2014) e os princípios de aprendizagem propostos por Gee (2005). Em um segundo momento, é apresentada a metodologia que envolveu o presente estudo, para logo em seguida detalhar os dados obtidos a partir da análise realizada com o jogo em questão, e finalizando com as considerações finais da pesquisa.

\section{Critérios de análise de jogos: avaliação de recurso digital e princípios de aprendizagem}

\footnotetext{
"São crianças e adolescentes ao redor do mundo que preferem passar horas em frente a um jogo de computador ou videogame a ter de fazer qualquer outra coisa". (Mcgonical, 2012, p.12)
}

A autora McGonical resume bem o tamanho interesse dos jovens e crianças por jogos digitais, e se tratando desses adeptos, é preciso, o professor, compreender que são esses os alunos que integram as salas de aula. No entanto, apenas estar ciente desta interface escolar e adotar quaisquer ferramentas tecnológicas não garante o sucesso na missão de ensinar. É preciso, por parte do educador, muito mais do que ser consciente da realidade, é preciso compreender o processo que envolve inserir jogos digitais em sala de aula, o qual começa no seu planejamento.

Para utilizar jogos digitais na educação, há pré-requisitos primordiais, e um deles é a necessidade de realizar a avaliação do recurso, a fim de identificar se o mesmo tem capacidade de promover a aprendizagem ao mesmo tempo em que desperta o interesse do aluno (Centenaro, 2016; Centenaro; Reis, 2017). É preciso analisar, levar alguns critérios em consideração para então ter a certeza de que o jogo é bom para o ensino e então partir para a sua aplicação em sala de aula. 
Assim, um dos critérios possíveis de serem utilizados por professores para a seleção correta da tecnologia são os princípios de aprendizagem, que para Gee (2005) são características fundamentais que bons jogos para o ensino possuem. Outro critério é o conjunto de elementos avaliativos de recursos digitais elaborados por Reis e Gomes (2014), nos quais permite o educador conhecer mais sobre o jogo, como, por exemplo, os seus aspectos linguísticos, pedagógicos e tecnológicos.

No que se refere aos princípios de aprendizagem, Gee (2005) aponta que jogos capazes de auxiliar na construção cognitiva do aluno dispõem de bons elementos no seu ambiente virtual, os quais auxiliam o aluno a aprender mesmo que esse não tenha consciência disso. Desta forma, o autor, em sua obra Good video games and good learning (2005) propõe 16 elementos, os quais são apresentados na Tabela 1.

Tabela 1 - Princípios de aprendizagem.

\begin{tabular}{|l|}
\hline Princípio de aprendizagem \\
\hline Identidade \\
\hline Interação \\
\hline Risco \\
\hline Produção \\
\hline Customização \\
\hline Agência \\
\hline Boa ordenação dos problemas \\
\hline Desafio e consolidação \\
\hline Na hora certa \\
\hline Sentidos contextualizados \\
\hline Frustração prazerosa \\
\hline Pensamento sistemático \\
\hline Explorar, pensar lateralmente e repensar os objetivos \\
\hline Ferramentas inteligentes \\
\hline Equipes transfuncionais \\
\hline Performance anterior a competência \\
\hline
\end{tabular}

Para compreender melhor, cada um desses elementos atua significativamente (sentidos contextualizados) em jogo, desenvolvendo no jogador sua autoconfiança, autonomia e novos conhecimentos, pois o faz com que se sinta parte do ambiente, seja por meio de um avatar (identidade), da sua capacidade de alterar o cenário (produção) ao seu favor (customização) ou por meio do poder de liderar suas ações e escolher a ordem de seus desafios (agência).

Além disso, um bom jogo instiga o seu usuário a enfrentar as missões, mesmo que essas apresentam o risco de perder ou ganhar (risco). No entanto, se mesmo assim fracassar, é dado a chance de recomeçar onde parou, para tentar novamente (frustração prazerosa), e isso faz, o jogador, repensar em novas estratégias até conquistar o seu objetivo (explorar, pensar lateralmente, repensar os objetivos).

Para Gee (2005), de acordo com os elementos, os desafios não são nem tão fáceis ou difíceis a ponto de desmotivar o jogador (desafio e consolidação), sendo esses organizados da mais fácil para a mais difícil (boa ordenação dos problemas). Assim, os bons jogos para o autor, disponibilizam ao jogador missões nos quais o usuário pode usar suas habilidades e realizar ações interligadas entre si (pensamento sistemático), o que os capacita a conquistar os desafios (performance anterior a competência). Porém, essas conquistas também acontecem porque o jogo oferecer subsídios extras para quem os joga, como, por exemplo, recursos do ambiente virtual (ferramentas inteligentes), feedbacks (na hora certa) e a interação (interação) com demais jogadores (equipes transfuncionais), facilitando assim, seu desempenho no jogo. 
Juntamente aos princípios de aprendizagem de Gee, há outro fator importante que auxilia professores na análise de jogos digitais, são os critérios de avaliação de recurso digital que Reis e Gomes (2014) elaboraram. Esses têm como finalidade auxiliar o professor a compreender os aspectos linguísticos, pedagógicos e tecnológicos presentes no jogo escolhido, como é ilustrado na Figura 1.

\begin{tabular}{|c|c|}
\hline \multicolumn{2}{|r|}{ Dados de identificação do recurso } \\
\hline \multicolumn{2}{|l|}{ URL: } \\
\hline \multicolumn{2}{|l|}{ Acesso em: } \\
\hline \multicolumn{2}{|l|}{ Avaliado por: } \\
\hline Recursos digitais & Indicadores \\
\hline Aspectos linguísticos & $\begin{array}{l}\text { - Objetivo; } \\
\text { - Tema; } \\
\text { - Registro da linguagem; Grau de (in)formalidade da } \\
\text { linguagem; } \\
\text { - Eventos comunicativos; }\end{array}$ \\
\hline Aspectos pedagógicos & $\begin{array}{l}\text { - Concepção de linguagem; } \\
\text { - Níveis de ensino (básico, pré-intermediário, } \\
\text { intermediário e avançado); } \\
\text { - Habilidade linguística; } \\
\text { - Abordagem de ensino aprendizagem; }\end{array}$ \\
\hline Aspectos tecnológicos & $\begin{array}{l}\text { - Formato do recurso; } \\
\text { - Duração; } \\
\text { - Possibilidade de download; } \\
\text { - Transição de áudio; } \\
\text { - Possibilidade de inserir comentário; } \\
\text { - Atualização dos recursos. }\end{array}$ \\
\hline
\end{tabular}

Figura 1 - Critérios de avaliação dos recursos digitais (Reis; Gomes, 2014, p.378).

Assim, Reis e Gomes (2014) sugerem que o professor deve inicialmente buscar identificar o objetivo do recurso, o tema abordado, o grau de formalidade da linguagem utilizada e os eventos comunicativos que dão suporte para a interação e uso da linguagem empregada no recurso digital, neste estudo, jogos digitais. Esses itens são chamados pelos autores de aspectos linguísticos.

De mesma forma, os autores pontuam a importância da análise dos aspectos pedagógicos, que oferecem suporte para fundamentar a proposta pedagógica de um software ou de um recurso tecnológico em estudo, como, por exemplo, considerar o nível de conhecimento linguístico que a ferramenta exige de seu usuário, para que ele compreenda suas instruções encontradas, o que pode ser nos níveis básico, préintermediário, intermediário e avançado.

Por fim, com relação aos aspectos tecnológicos, os autores destacam que é nesse momento que se observa os aspectos técnicos do recurso. No caso dos jogos digitais, é levado em consideração o tamanho do software, se é um jogo leve ou pesado (em que computadores rodam esses jogos? Exigem ampla conexão/bandagem?). Em conjunto, também é identificada nesse momento, a disponibilidade de download, a existência de transcrição dos áudios e a modalidade multiplayer, bem como a possibilidade de inserir comentários e comunicar-se com outros usuários por meio do ambiente virtual, além de saber com que frequência é feita as atualizações no recurso.

A partir do entendimento de cada um dos dois critérios selecionados para a análise de jogos digitais neste estudo, se é preciso compreender que nem todos os jogos digitais disponíveis são considerados bons jogos para o ensino, e que professores necessitam avaliar estes recursos com base em experiências empíricas, como é o caso das investigações realizadas por Gee (2005) e Reis e Gomes (2014). Somente assim, o 
ensino por meio do uso de tecnologias, poderá ser condizente tanto para alunos quanto para professores.

\section{Metodologia da pesquisa}

No segundo semestre de 2015 o jogo Mission $U s^{3}$ foi escolhido por meio de uma investigação aleatória realizada por membros do grupo GrPesq/NUPEAD ${ }^{4}$, que buscou por jogos sérios gratuitos de Língua Inglesa em pesquisa no Google. O presente estudo teve papel fundamental em pesquisa de mestrado realizada na Universidade Federal de Santa Maria que investigou uma abordagem de aplicação de jogos digitais para o ensino de Língua Inglesa.

A análise do jogo, segundo os critérios apresentados na seção anterior, iniciou-se com a professora-pesquisadora jogando todos os cinco níveis disponíveis na plataforma virtual, através dos quais completou todos os desafios que o recurso oferece a um jogador. Ao término de cada fase concluída, foram levantados dados sobre os aspectos linguísticos, pedagógicos e tecnológicos da ferramenta (Reis; Gomes, 2014), da mesma forma que foram identificados quais dos princípios de aprendizagem propostos por Gee (2005), o jogo Mission US, apresentava em sua interface, com a finalidade de identificar seu potencial em sala de aula de Língua Inglesa.

\section{Análise do jogo digital Mission US: critérios de avaliação de recurso digital e princípios de aprendizagem}

No que se refere aos critérios estabelecidos por Reis e Gomes (2014) na avaliação de recursos digitais, o Mission US é um jogo sério, isto é, desenvolvido com propósitos educacionais ${ }^{5}$, disponibilizado gratuitamente em formato online digital no idioma Inglês. Esse jogo foi desenvolvido por colaboradores da WNET em conjunto com uma equipe multidisciplinar que desenvolve e testa jogos. O objetivo da ferramenta é promover a imersão de estudantes que se encontram nos níveis escolares do Ensino Fundamental e Ensino Médio (nível de ensino) para desvendarem "problemas históricos e contemporâneos de forma a encorajar troca de perspectivas, discussão e ponderação sobre os eventos históricos da América" (Mission US, 2016) (tema).

Como são apresentados na Figura 2, os contextos históricos discutidos no jogo digital são, por exemplo, o massacre de civis em Boston no ano de 1777; a procura por liberdade vivida por negros Afro-Americanos em 1850; os confrontos travados a partir de 1886, na expansão de território dos EUA e da chegada de imigrantes ao país em 1907.

\footnotetext{
${ }^{3}$ http://www.mission-us.org/

4 Núcleo de Pesquisa, Ensino e Aprendizagem de Línguas a Distância da Universidade Federal de Santa Maria.

5 Mesmo sendo um jogo sério, a presente análise se fez necessário uma vez que o recurso foi desenvolvido para o ensino de História. Assim, a importância de avaliar também, sua potencialidade para o ensino de Língua Inglesa.
} 

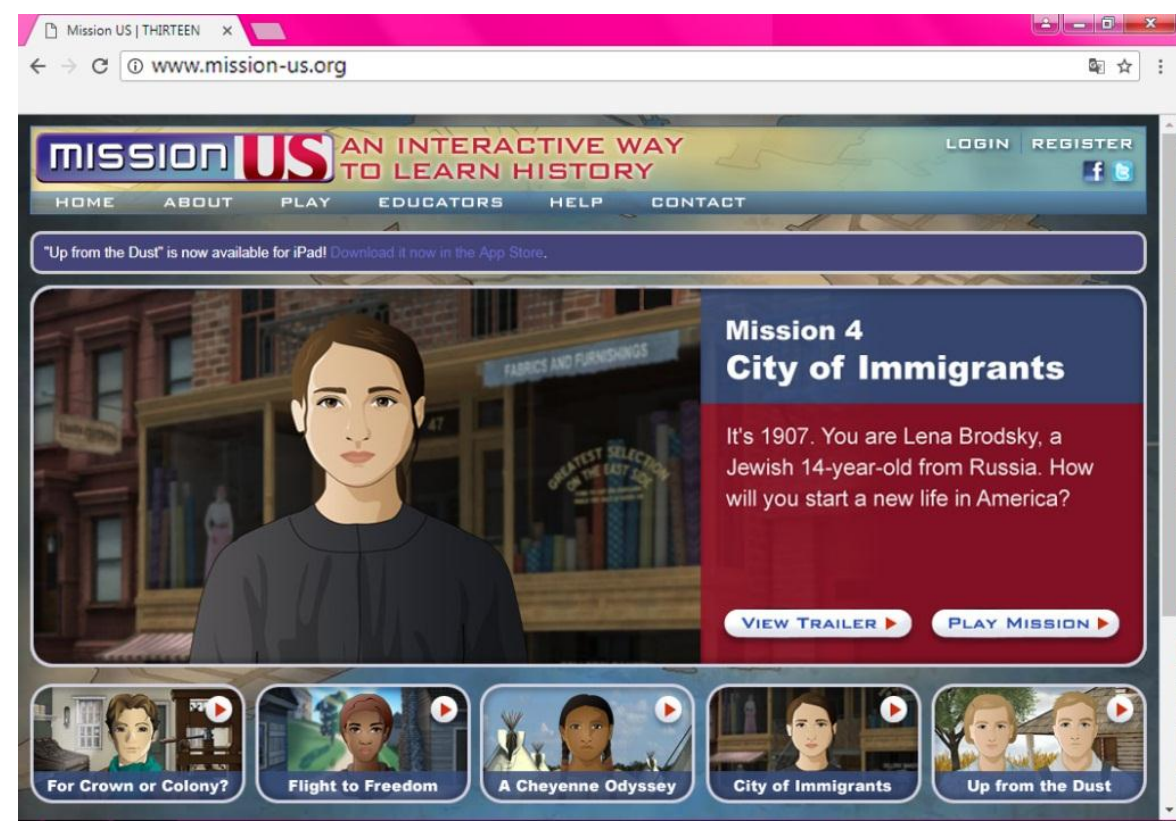

Figura 2 - Site do jogo MUS e os contextos históricos abordados nos jogos ${ }^{6}$.

A narrativa do jogo inicia com a vinda da personagem Lena, uma imigrante judia da Rússia que imigrou para os Estados Unidos com a intenção de trabalhar para juntar dinheiro e trazer seus pais para morar na América. As experiências vivenciadas pela personagem, nas suas primeiras semanas em um novo país, oferecem ao jogador a imersão no jogo e no engajamento de ações formais (registro de linguagem) as quais o levam a escolher os melhores caminhos para guiar Lena a conquistar o seu objetivo, que é arrecadar dinheiro.

Assim, nessa jornada, o jogador interage com diferentes personagens do jogo e com o ambiente virtual por meio de diálogos textuais e orais (eventos comunicativos). No cenário, a transcrição do áudio é disponibilizada, de modo a auxiliar o aluno a desenvolver a leitura multimodal, compreensão oral e compreensão escrita da língua para resolver os desafios ao longo dos cinco níveis (duração). Esses desafios iniciam na sala de imigração da Ilha de Ellis, até, inclusive, levando os alunos a assumir o papel de Lena e realizarem entrevistas de emprego em fábricas.

O Mission US também oferece ao professor material extra, o qual é atualizado semestralmente para ser utilizado como guia em sala de aula (atualização do recurso). Além disso, atividades online que exploram tanto os vocabulários quanto as linguagens apresentadas em jogo (ver Figura 3) podem ser encontradas no site.

\footnotetext{
${ }^{6}$ http://www.mission-us.org/
}

V. $15 \mathrm{~N}^{\circ}$ 2, dezembro, 2017 


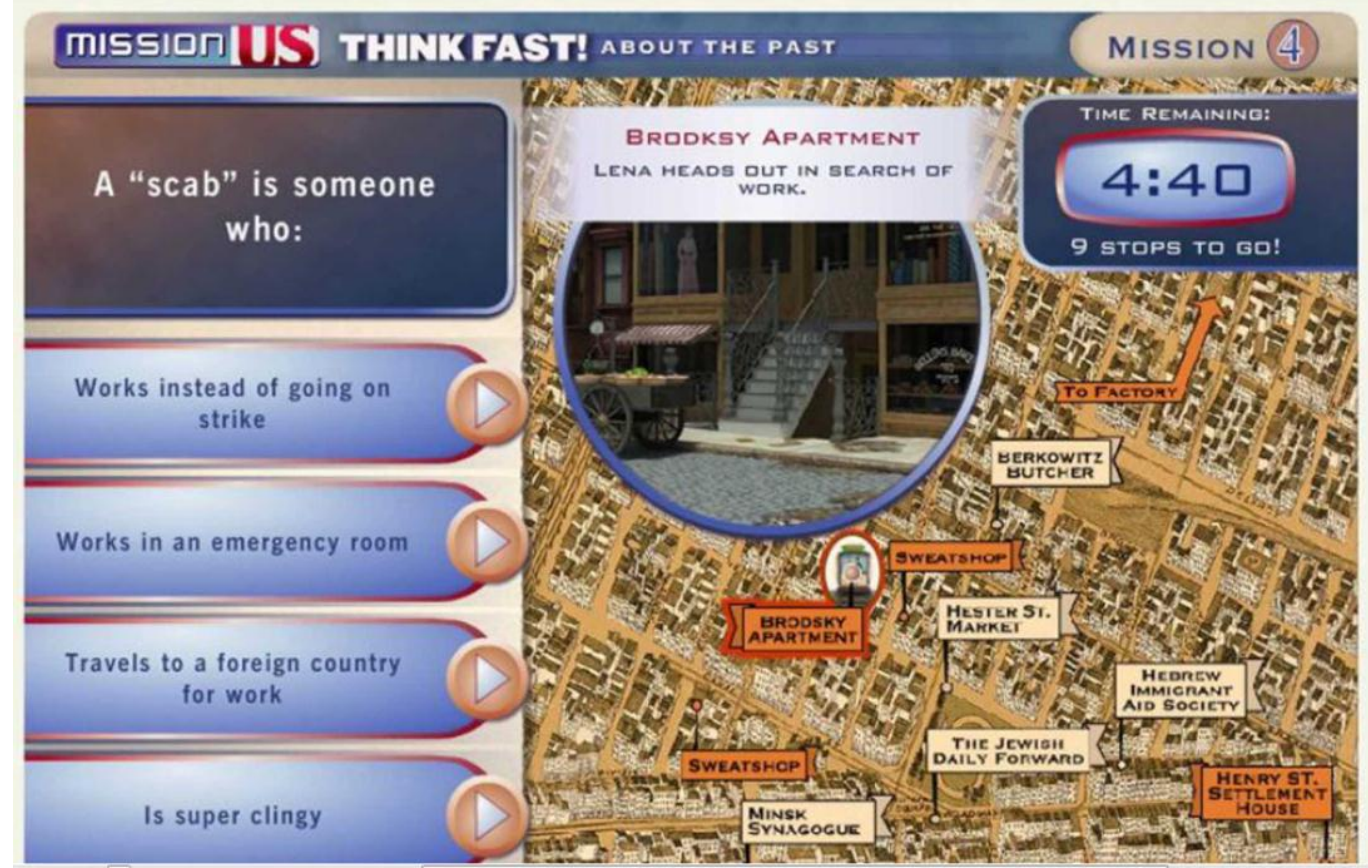

Figura 3 - Atividade que explora vocabulários ${ }^{7}$.

Quanto ao nível linguístico utilizado no recurso, esse exige do jogador conhecimento pré-intermediário e intermediário (habilidades linguísticas), haja vista que as situações comunicativas expostas apresentam desafios que exigem um grau maior de conhecimento na Língua Inglesa, como é mostrado na Figura 4. Nessa situação, o jogador atuando como a personagem Lena deve entender expressões como "was going to", "not realize yet", "I can help" e "work as hard as", por meio de vocabulários, tais como "misfourtune", "hard" e "business", e outras expressões geralmente estudadas em um nível pré-intermediário.

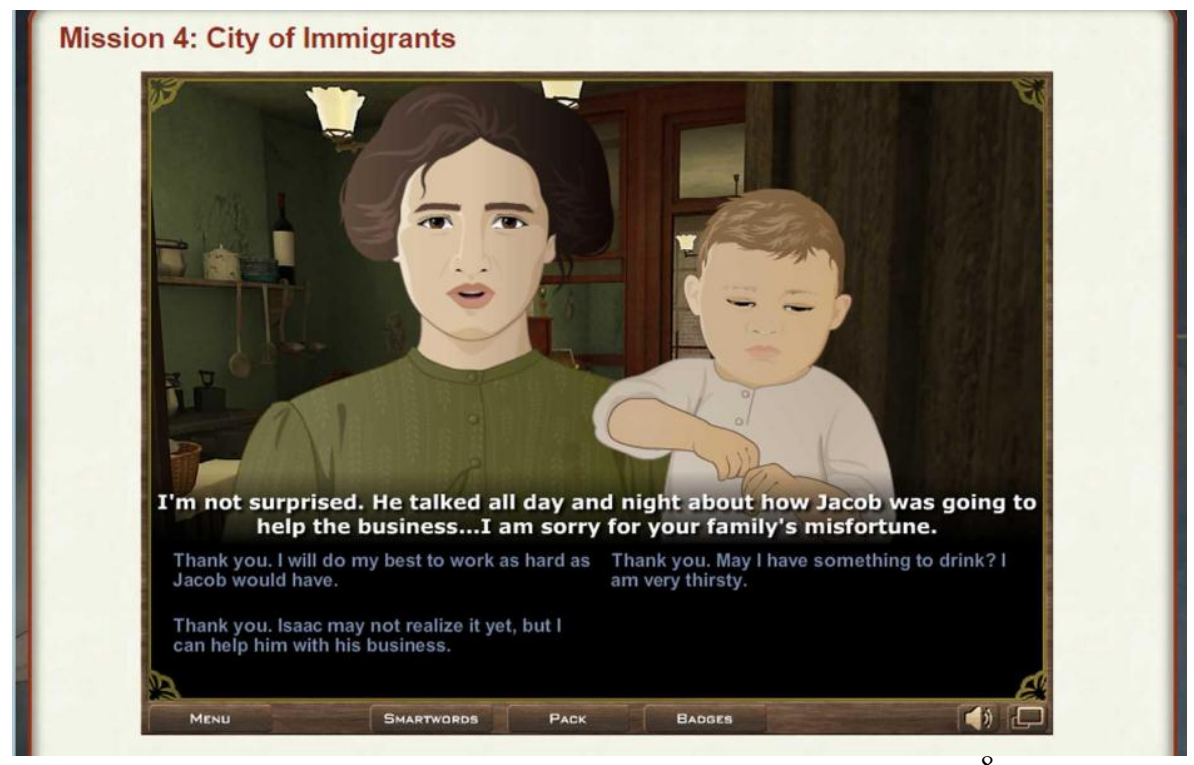

Figura 4 - Nível linguístico empregado no jogo ${ }^{8}$.

Com relação à concepção de linguagem, o jogo demonstra ser Sóciointeracionista, pois durante os desafios, o usuário constrói seu conhecimento linguístico

\footnotetext{
${ }_{8}^{7}$ http://www.mission-us.org/pages/mission-4-educator-guide-activities

8 http://www.mission-us.org/pages/mission-4
}

V. $15 \mathrm{~N}^{\mathrm{o}} 2$, dezembro, 2017 
por meio das interações que realiza com o ambiente virtual e demais personagens, já que "na ausência do outro o homem não se constrói" (Vygotsky, 2002, p. 235). Assim, o jogador aprende por meio de trocas recíprocas dentro de um meio social contextualizado (Rego, 1999), o qual é apresentado em jogo. Exemplo disso é ilustrado na Figura 5, em que a personagem Lena troca informações com outro personagem em jogo.

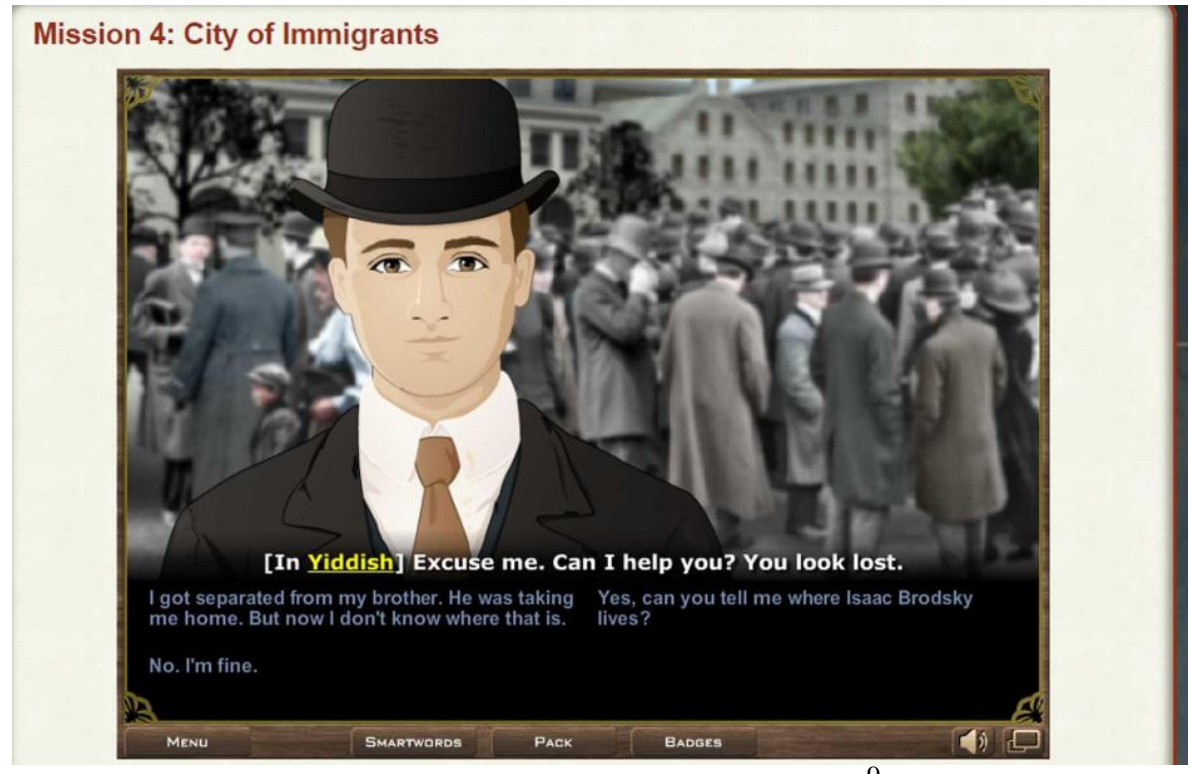

Figura 5 - Interação oral e textual ${ }^{9}$.

Além da avaliação dos aspectos linguísticos, tecnológicos e pedagógicos sugeridos por Reis e Gomes (2014), para a presente análise, foi também, identificado os princípios de aprendizagem propostos por Gee (2005), os quais foram importantes para aferir se a ferramenta apresentava os elementos que, segundo o autor, caracterizam bons jogos para o ensino. Assim, ao término da investigação, verificou-se que dos 16 princípios, o jogo Mission US apresenta 13 (ver Tabela 2), o que levou a concluir que esse recurso digital pode ser explorado em sala de aula.

Tabela 2 - Análise segundo princípios de aprendizagem.

\begin{tabular}{|l|c|}
\hline Princípio de aprendizagem & Possui? \\
\hline Identidade & Sim \\
\hline Interação & Sim \\
\hline Risco & Sim \\
\hline Produção & Não \\
\hline Customização & Sim \\
\hline Agência & Não \\
\hline Boa ordenação dos problemas & Sim \\
\hline Desafio e consolidação & Sim \\
\hline Na hora certa & Sim \\
\hline Sentidos contextualizados & Sim \\
\hline Frustração prazerosa & Sim \\
\hline Pensamento sistemático & Sim \\
\hline Explorar, pensar lateralmente, repensar os objetivos & Sim \\
\hline Ferramentas inteligentes & Sim \\
\hline Equipes transfuncionais & Não \\
\hline Performance anterior a competência & Sim \\
\hline
\end{tabular}

\footnotetext{
${ }^{9}$ http://www.mission-us.org/pages/mission-4
}

V. $15 \mathrm{~N}^{\circ}$ 2, dezembro, 2017 
Por fim, a partir da análise do Mission US, foi possível verificar o potencial do jogo para uso nas práticas pedagógicas de Língua Inglesa, ao mesmo tempo em que viabilizou a professora-pesquisadora a identificar como os níveis do jogo eram estruturados, seu sistema de feedbacks, ordem dos desafios, interação com o ambiente virtual e demais avatares, nível linguístico e habilidade de letramento digital exigido do usuário. Além disso, a educadora pode ter conhecimento sobre os assuntos e as interações linguísticas possíveis de serem explorados em atividades complementares durante as futuras aplicações em sala de aula.

\section{Considerações finais}

Ao analisar o jogo Mission US, pode-se compreender que o jogo é uma ferramenta capaz de potencializar o ensino de Língua Inglesa. De mesma forma, a presente análise demonstrou que os dois critérios adotados, avaliação de recurso digital (Reis; Gomes, 2014) e os princípios de aprendizagem (Gee, 2005), são critérios importantes de serem utilizados com demais jogos digitais. Isso se deve, pois auxiliam o professor a conhecer mais sobre a tecnologia, dando a ele capacidade de melhor explorar a ferramenta no ensino.

Também, a partir deste estudo realizado com o jogo Mission US é possível inferir que jogos digitais podem ser boas ferramentas para o ensino de Língua Inglesa, mesmo que, o jogo escolhido pelo professor não seja voltado para o ensino de línguas. Cabe aqui, o educador compreender os passos para analisar, e realizar com base em estudos científicos, verificando sempre quais os melhores métodos ou critérios para serem utilizados em análise de jogos.

Assim, é do professor a responsabilidade de avaliar se o recurso é apto ou não a corroborar com o ensino que deseja apresentar para os alunos, além de, o mesmo, ir à busca por mais critérios que confirmem ou neguem a potencialidade da ferramenta. Somente com a dedicação e empenho do professor, anterior a aplicação em sala de aula, o ensino pode ser produtivo, agregando o interesse dos estudantes ao mesmo tempo em que apresenta um ensino de qualidade.

\section{Referências bibliográficas}

CENTENARO, F. K. Investigação de uma abordagem pedagógica para o ensino de língua inglesa por meio de jogos digitais. Dissertação (Mestrado em Tecnologias Educacionais em Rede) - Universidade Federal de Santa Maria, 2016.

; REIS, S.C. Jogos Digitais em Sala de Aula de Língua Inglesa: investigação de uma proposta de gestão pedagógica para o ensino. Revista Linguagem \& Ensino, v. 20, n. 1, 2017.

GEE, J. P. Good video games and good learning. PHI KAPPA PHI FORUM, v. 85, n.2, 2005 .

GUERRA, D. AIÚ: A herança africana dos jogos de mancala no Brasil. Revista África e Africanidades, ano 2, n. 6, 2009.

MARCO, F. F. Atividades computacionais de ensino na formação inicial do professor de matemática. Campinas, São Paulo, 2009. 
MARINHO, S. P. P. Novas Tecnologias e Velhos currículos já é hora de sincronizar. São Paulo: Revista E-Curriculum, v. 2, n. 3, 2006.

MCGONICAL, J. A realidade em jogo: por que os games nos tornam melhores e como eles podem mudar o mundo. Rio de Janeiro: BestSeller, 2012.

MORAN, J. Desafios que as tecnologias digitais nos trazem. In MORAN, J.; MASETTO, M.; BEHRENS, M. Novas Tecnologias e Mediação Pedagógica. Campinas: Papirus, Ed. 21, 2013

PERTESON, M. Learner interaction in a massively multiplayer online role playing game (MMORPG): A sociocultural discourse analysis. ReCALL, Volume 24, 2012. p. $361-380$.

REGO, T. C. Vygotsky: uma perspectiva histórico-cultural da educação. Petrópolis: Vozes, 1999.

REIS, S. C.; GOMES, A. Podcasts para o ensino de Língua Inglesa: análise e prática de letramento digital. Calidoscópio, v. 12, n. 3, 2014. p. 367-379.

SANCHES, K.; RAMOS, A.; COSTA, F. As tecnologias digitais e a necessidade da formação continuada de professores de Ciências e Biologia para tecnologia: um estudo realizado em uma escola de Belo. Revista Tecnologias na Educação, Ano 6, n. 11, 2014.

VYGOTSKY. Formação social da mente. São Paulo, Martins Fontes, 2002. 